\title{
Boundary-related durations in Modern Greek
}

\author{
Evia Kainada \\ Department of Linguistics and English Language, University of Edinburgh, UK \\ Department of Linguistics and Phonetics, University of Leeds, UK \\ https://doi.org/10.36505/ExLing-2010/03/0018/000138
}

\begin{abstract}
This paper investigates the influence of prosodic boundary strength on the temporal organisation of speech. It tests whether Modern Greek (MG) exhibits pre- and postboundary lengthening, and whether the lengthening effect decays gradually the further away from the boundary, or is attracted to stressed syllables, even if those are not in the proximity of the boundary. It is shown that MG exhibits pre-boundary lengthening, which is at its strongest on the pre-boundary syllable, followed in strength by the stressed syllable, and is least pronounced on the intervening unstressed syllables. No clear post-boundary lengthening effects were identified.
\end{abstract}

Key words: prosodic structure, pre- and post-boundary lengthening, Modern Greek

\section{Introduction}

It is a well-attested phenomenon that the duration of segments at the vicinity of prosodic boundaries is influenced by the strength of the boundary, i.e. longer durations are generally found in pre- and often postboundary positions close to stronger prosodic boundaries (Wightman et al. 1992, Cho \& Keating 2001). This phenomenon is known as pre- and post-boundary lengthening.

The first question addressed in this study is whether pre- and post-boundary lengthening is attested in $\mathrm{MG}$, as indirectly suggested by previous research (e.g. Baltazani 2006). In post-boundary positions, Botinis (1989) and Arvaniti (2000) have shown that low order prosodic constituents do not exhibit post-boundary lengthening, but there has been no research testing the effect in higher order domains.

The theory of $\pi$-gestures (Byrd \& Salzman 2003) proposes that the boundary strength slows down the movements in the vicinity of the boundary, therefore the effect is at its strongest closer to the boundary and cannot skip syllables. Turk \& Shattuck-Hufnagel (2007), on the other hand, reported that stressed syllables could attract a boundary-related lengthening, irrespectively of whether unstressed syllables intervene between the prominent syllable and the pre-boundary one. The second question of this paper is whether the stressed syllable of the preboundary word attracts a lengthening effect or not in MG when further away from the boundary.

ExLing 2010: Proceedings of 3rd Tutorial and Research Workshop on Experimental Linguistics, 25-27 August, Athens, Greece 


\section{Method}

\section{Materials}

The boundary strength effect was tested on the duration of pre- and postboundary syllables. The materials consisted of ADJECTIVE \# NOUN structures (\#=prosodic boundary of varying strength). The pre-boundary word was tetrasyllabic stressed on the antepenultimate syllable, and the post-boundary word was at least trisyllabic stressed on the second syllable. Sentences were designed to manipulate the boundary strength by changing the syntactic affiliation of the words, and the length of the phrases ( 8 items*5 boundary conditions $* 2$ repetitions $* 5$ speakers $=400$ utterances). Following is an example of the boundary conditions (BC1-5 in increasing size):

BC1 [a'po a'ftin tin ci'notopi \# ko'pela, to pe'rimena] from this the common girl it expected PASTIMP-1s $_{\text {sir }}$ 'From this common girl, I expected it'.

BC2 [me em'fanisi ci'notopi, \# ko'pela ðen Өa vri] with appearance common girl not will ${ }_{\mathrm{AUX}}$ find $_{\mathrm{FUT}-3 \mathrm{~s}}$ 'With a common appearance, he will not find a girl'.

BC3 [a'fu 'eçis em'fanisi ci'notopi, \# ko'pela ðen Өa vris] since have PRES-2s appearance common girl not will AUX $_{\text {find }}$ FUT-2s $_{\text {s }}$ 'Since you have a common appearance, you will not find a girl'.

BC4 [a'fu 'eçis ka'ta jeni'ki omolo'jia em'fanisi ci'notopi, \# ko'pela ðen Өa vris 'xoris rizi'ki ala'ji]

since have $\mathrm{PRES}-2 \mathrm{~s}_{\mathrm{S}}$ by general consent appearance common girl not will ${ }_{\mathrm{AUX}}$ find $_{\mathrm{FUT}-2 \mathrm{~s}}$ without radical change

'Since by general consent you have a common appearance, you will not find a girl without a radical change'.

BC5 ['eçis ka'ta jeni'ki omolo'jia em'fanisi ci'notopi. \# ko'pela ðen Өa vris 'xoris rizi'ki ala'ji]

have $_{\mathrm{PRES}-2 \mathrm{~S}}$ by general consent appearance common girl not will $\mathrm{AUX}_{\mathrm{Aind}}$ fiUT-2S $_{\mathrm{F}}$ without radical change

'By general consent you have a common appearance. You will not find a girl

without a radical change'.

\section{Participants and Recordings}

Five native speakers of $\mathrm{MG}$, two male and three female, were recorded. They were all in their twenties at the time of the recordings and were students of the University of Edinburgh, having lived in the UK for a period of time no longer than a year. None reported a speech, hearing, or reading difficulty. Recordings took place at the recording booth of the University of Edinburgh. 


\section{Results}

Results on the duration of the ultimate, penultimate and antepenultimate syllable of the pre-boundary word are reported, and of the first postboundary syllable (measurements for the onset, rime and whole syllable). The effect on their duration was tested using repeated measures ANOVAs. Boundary strength was found to be significant on the onset, rime and whole syllable of the antepenultimate, penultimate and ultimate syllables of the preboundary word [ULTIMATE syllable: onset: $F(4,244)=37.4$, p <.001, rime: $F(4,244)=43.4, \quad \mathrm{p}<.001, \quad$ whole syllable: $F(4,228)=53.6, \quad \mathrm{p}<.001$, PENULTIMATE syllable: onset: $F(4,160)=10.7, \mathrm{p}<.001$, rime: $F(4,132)=4.7$, $\mathrm{p}<.001$, whole syllable: $F(4,132)=14.3, \mathrm{p}<.001$, ANTEPENULTIMATE syllable: onset: $F(4,128)=6.38, \mathrm{p}<.001$, rime: $F(4,128)=19.55, \mathrm{p}<.001$, whole syllable: $F(4,128)=22.2, \mathrm{p}<.001]$. In post-boundary position, the boundary strength effect was found to be significant only for the onset of the postboundary syllable $(F(3,180)=3.76, \mathrm{p}=.012)$, however no clear cumulative pattern was found (duration of onset: $\mathrm{BC} 1=70 \mathrm{~ms}, \mathrm{BC} 2=73 \mathrm{~ms}, \mathrm{BC} 3=77 \mathrm{~ms}$, $\mathrm{BC} 4=75 \mathrm{~ms}$, BC5=68ms, but see also Katsika 2009).
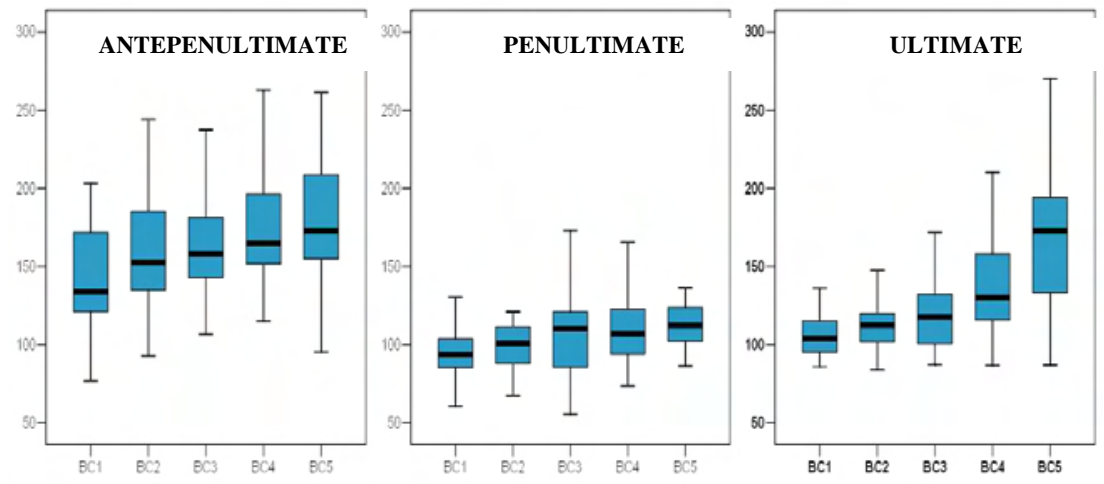

Figure 1. Duration (ms) of antepenultimate (stressed), penultimate and ultimate syllables of pre-boundary word for all boundary conditions (BC1$5)$.

The magnitude of the boundary strength effect was then examined on each syllable; the percent lengthening of $\mathrm{BC} 2-\mathrm{BC} 5$ with respect to $\mathrm{BC} 1$ was calculated $\left(\mathrm{BC}_{2345 \text { lengthening }}=\left[\left(\mathrm{BC}_{2345}\right.\right.\right.$ duration- $\mathrm{BC} 1$ duration $\left.) * 100\right] /$ $\mathrm{BC}$ 1duration) and was found to be significant for all three syllables [ULTIMATE $F(3,171)=43.191, \mathrm{p}<.001$, PENULTIMATE $F(3,99)=5.97, \mathrm{p}=.001$, ANTEPENULTIMATE $F(3,96)=9.5, \mathrm{p}<.001]$. It was most pronounced for the pre-boundary syllable: the percent lengthening starts from about $10 \%$ (BC1 to $\mathrm{BC} 2$ ) and reaches up to $60 \%$ (BC1 to $\mathrm{BC} 5)$. The antepenultimate 
(stressed) syllable followed in terms of magnitude of lengthening (15\% from $\mathrm{BC} 1$ to $\mathrm{BC} 5$ reaching up to $31 \%$ for $\mathrm{BC} 1$ to $\mathrm{BC} 5$ ), and it was the least pronounced for the intervening unstressed syllable $(8 \%$ for $\mathrm{BC} 1$ to $\mathrm{BC} 2$ reaching up to $22 \%$ for $\mathrm{BC} 1$ to $\mathrm{BC}$ ).

\section{Discussion}

This paper showed that MG exhibits a clear pre-boundary lengthening pattern. In post-boundary position the result is less clear showcasing a possible asymmetry between the two positions. Importantly, the effect of boundary strength in MG seems to support Turk \& Hufnagel's (2007) finding that boundary-induced lengthening seems to be attracted to prominent syllables, and is not necessarily in line with the prediction by the $\pi$-gestures theory (Byrd \& Saltzman 2003). However, the present paper did find a pre-boundary lengthening effect in the intervening unstressed syllable, which was not as pronounced as the one on the stressed syllable.

\section{Acknowledgements}

I would like to thank Prof. D. R. Ladd and Prof. A. Turk for their constant support and comments throughout my research. This study was funded by the Economic and Social Research Council, UK.

\section{References}

Arvaniti, A. 2000. The phonetics of stress in Greek, Journal of Greek Linguistics 1, 9-39.

Baltazani, M. 2006. Focusing, prosodic phrasing, and hiatus resolution in Greek, in L. Goldstein, D. Walen \& C. Best, eds, Proceedings of Laboratory Phonology VIII, Mouton de Gruyter, Berlin, pp. 473-494.

Botinis, A. 1989. Stress and Prosodic Structure in Greek, Lund University Press.

Byrd, D., Saltzman, E. 2003. The elastic phrase: Modeling the dynamics of boundary-adjacent lengthening, Journal of Phonetics 31(2), 149-180.

Cho, T., Keating, P. 2001. Articulatory and acoustic studies on domain initial strengthening in Korean, Journal of Phonetics 29, 155-190.

Katsika, A. 2009. The interaction of boundaries and prominence in Greek, poster presentation at the $157^{\text {th }}$ Acoustical Society of America, May 2009.

Nespor, M., Vogel, I. 1986. Prosodic Phonology, Foris Publications.

Turk, A., Shattuck-Hufnagel, S. 2007. Multiple targets of phrase-final lengtheningin American English words, Journal of Phonetics 35, 445-372.

Wightman, C.W., Shattuck-Hufnagel, S., Ostendorf, M., Price, M.J. 1992. Segmental durations in the vicinity of prosodic phrase boundaries, Journal of the Acoustical Society of America 91, 1707-1717. 